2.

\title{
Ueber die künstliche Darstellung von harnsauren Salzen in der Form von Sphärolithen.
}

Aus der medicinischen Universitätsklinik in Göttingen.

Von Wilhelm Ebstein und Arthur Nicolaier.

(Mit 1 Zinkographie.)

Wir haben die Beoachtung gemacht, dass es mühelos gelingt, harnsaure Salze in der Form von Sphärolithen künstlich darzustellen. Man kann sich von der Ricbtigkeit dieser Behauptung sehr leicht durch folgenden Versuch überzeugen:

Wenn man anf einem Objectträger Harnsäure mit verdïnnten Jösungen von Alkalien zusammenbringt, so wird bekanntilich je nach der Concentration der letzteren die Harnsäure ganz oder theilweise aufgelöst. Verfolgt man nun die in der alkalischen Lösung der Harnsäure eintretenden Vorgänge unter dem Mikroskop, so sieht man schon bei scbwacher Vergrösserung gewöhnlich zunächst aw Rande des Präparates, anfänglich in der vorbandenen Flässigkeit herumschwimmend, kleine Bildungen auftreten, von deren Kugelform man sich leicht überzeugen kann. Kommen dieselben nach dem Verdunsten der Flüssigkeit zur Ruhe, so ersebeinen sie als kreisrunde Figuren. Die Zabl derselben nimmt in demselben Verhältniss, in dem die Barnsäure in dem Alsali sich löst, mehr oder weniger $z u$ und wird bäufig eine sebr erhebliche. Die Grösse dieser Bildungen schwankt in. ziemlich weiten Grenzen. Während wir solche von nur $2 \mu$ Durchmesser fanden, erreichten die grössten, welche wir sahen, einen Durchmesser von $100 \mu$.

Betrachtet man diese kreisrunden Figuren bei etwas stärkerer Vergrösserung, so sieht man, dass sie eine concentrische Schichtung zeigen. Die Zabl dieser Schichten ist immer nur eine sehr beschränkte. Diese Bildungen baben eine bellstrohgelbe Farbe oder sind völlig farblos. Neben ibnen finden sich in dem Präparat mehr oder weniger zablreiche nadelformige Krystalle, die theils einzeln, theils zu bündel-oder kreisförmigen Drusen gruppirt auftreten. Dieselben gleichen vollkommen denen, weiche man iu den typischen Ablagerungen bei Arthritis urica findet. Ausserdem beobachtet man in den Präparaten noch eine grössere oder geringere Zahl von Harnsäurekrystallen, so weit dieselben nicht von dem Alkali gelöst worden sind, von verschiedener Grösse, Krystallform und Farbe, je nachdem wir dazu chemisch vollkommen reine oder nicht völlig gereinigte Harnsäure oder die mebr oder weniger stark gefärbten Krystalle der Harnsäuresedimente aus 


\section{4}

menschlichem Harn verwendet hatten. Die letzteren verlieren, bevor sie in Lösung äbergeben, bei der Behandlung mit schwachen, alkalischen Lösungen ibren Farbstoff ${ }^{1}$ ). Wir bemerken hier zugleich, dass wir dieselben Bildungen bei gleicher Behandlung aus Uratsteinen, gichtischen Tophis und dem Sedilaentum lateritium des Menschenharnes dargestellt haben.

Als Lösungsmittel der Harnsäure benutzten wir schwache Lösungen von Aetznatron, Aetzkali, kohlensaurem Lithium, Borax, Dinatriumphosphat, Ammoniak und Piperazin. Die grössten derartigen Bildungen baben wir aus den Harnsäuresedimenten des menschlichen Harns, die kleinsten, wenn wir als Lösungsmittel der Harnsäure, beziehungsweise der Urate, Ammoniak oder Piperazin verwandten. Eine künstliche Färbung dieser Bildungen gelang in sehr schöner Weise mit verschiedenen Tinctionsflüssigkeiten. Wir benutzten Boraxcarmin, alkoholisch-alkalische Methylenblaulösung und Bismarkbraun. Die Farbstofflösungen wurden der Natronlauge in geringer Menge zugesetzt. Die Präparate lassen sich, nachdem sie getrocknet sind, in bekannter Weise in Canadabalsam oder Damaraharz, conserviren.

Untersucht man solche Präparate mit dem Polarisationsmikroskop zwischen gekreuzten Nicols, so überzeugt man sich erstens, dass die erwähnten kreisrunden Bildungen das rechtwinklige schwarze Interferenzkreuz der Sphärolithe zeigen, dessen Arme den Polarisationsebenen der Nicol'schen Prismen parallel la ufen, und $z$ weitens, dass ausser diesem Kreuz mit dem Mittelpunkt des Kreuzes concentrisch farbige Interferentringe vorbanden sind. Man sieht dieselben an den scharf auf das schwarze Interferenzkreuz eingestellten Sphärolithen beim Heben und Senken des Tubus oder aber ohne Aenderung der Tubuseiustellung an denjenigen Exemplaren der Sphärolithe, an welohen das schwarze Interferenzlreuz nicht deutlich sichtbar ist, weiche also wit den Sphärolithen, an denen dasselbe scharf zu sehen ist, nicht in einer Ebene liegen. Es scheinen sowohl die sauren wie die neutralen Salze der Barnsäure solche Sphärolithe bilden zu können, wofern man dies aus der Thatsache folgern darf, dass sie sich in den Lösungen der Harnsäure sowobl in ätzenden, als auch in kohlensauren Alkalien abscbeiden, wobei im ersteren Falle neutrale, im letzteren saure barnsaure Salze entstehen ${ }^{2}$ ). Wir lösten von chemisch reiner Harnsäure $0,5 \mathrm{~g}$ und $0,5 \mathrm{~g}$ Natron bicarbonicum, bezw.

1) Bierauf hat bereis früher einer von uns (Ebstein, Naturwissenschaftlicbe Rundschan. III. 1888. S. 109) aufmerksam gemacht. Hier heisst es: "Wenn man Harnsäurekrystalle mit verdünnten Alkalien vorsichtig behandelt, so lässt sich auf diese Weise der Farbstoff dieser Kryşalle extrabiren, und es bleibt eine manchmal geschichtete, die ursprïngliche Form der Krystalle beibehaltende, aber keine Eiweissreaction zeigende Substanz übrig, welche das licht doppelt bricht und durch Tinctionsmittel nicht färbbar ist." Es sind dies entfärbte Harnsäurekrystalle.

2) Vergl. Salkowski in Salkowski und Leube, Lehre vom Harn. Berlin 1882. S. 89 , 
$1 \mathrm{~g}$ und $0,5 \mathrm{~g}$ Aetznatron in je $200-250 \mathrm{~g}$ kochenden Wassers. Beim Erkalten setzte sich in beiden Lösungen ein theils aus isolirten, theils aus büschel- oder kreisförmig angeordneten Nadeln bestehendes Sediment ab. Aus dem Filtrat krystallisirteu unter den angegebenen Bedingungen Sphärolitbe aus; daneben auch spärlicbere oder reichlichere Nadeln in der gleichen Anordnung, wie eben beschrieben wurde.

Dass diese Sphärolithe sich in solchen alkalischen Lösungen der Harnsäure bilden können, könnte auffallend erscheinen, denn 0. Lehmann') sagt: „Es dïrfte kaum eine Substanz geben, bei welcher durch genügende Verdickung des Hösungsmittels und Bescbleunigung der Krystallisation Sphärolithbildung nicht beobachtet werden könnte." Deswegen begünstigt nach O. Lehmann ${ }^{2}$ ) die rasche Abküblung die Bildung von Sphärolithen und zwar sowohl wegen der mit zunehmenden Schnelligkeit der Krystallisation, wie auch wegen der mit sinkender Temperatur zunehmenden Viscosität der Flüssigkeit. Die von 0 . Lehmann angefübrten Bedingungen für die Bildung von Sphärolithen sind für unsere Sphärolithe nicht zutreffend. Es handelt sich dabei weder um zähflüssige Lösungen, noch um rasche Abküblung der Lösungen. Insbesondere mag hier noch erwähnt werden, dass es auch bei ganz plötzlicher Abküblung von Lösungen eines Sedimentum lateritium nicht gelingt, Sphärolithe zu erzeugen. Bekanntlich scheidet sich dabei eben wieder das Sedimentum lateritium in der früberen Form ab. Dagegen ist hier vielleicht die Ursache der Sphärolithbildung darin zu suchen, dass harnsaure Salze, wie die Niederschläge derselben in dem bekannten Uratsediment des Harns zeigen, im Allgemeinen schwer krystallisiren, und dass derartige schwer lsrystallisirende Körper in der Regel, wenn sie krystallisiren, zunächst in Sphärolithen auftreten. Dass eine gewisse Zähflüssigkeit der Uratlösungen der Bildung ron Sphärolithen zum mindesten nicht nngünstig ist, beweist die Thatsache, dass wir gleicbfalls Spbärolithe und zwar sehr schöne erhielten, weny wir zur Lösung der Harnsäure schwache alkalische Lösungen, denen etwas frisches Hübnereiweiss zugesetzt war, benutzten.

Schliesslich mag, was bisher nicht beobachtet zu sein scheint, noch bemerkt werden, dass auch die nur im ammoniakalischen Harn in Kugel-, Stechapfel- oder Morgensternform auftretenden harnsauren Salze, welche allgemein für harnsaures Ammoniak gehalten werden, das Kreuz der Sphärolithe zeigen.

Da unseres Wissens auf diese Erscheinungsweise der harnsauren Salze in Form von Sphärolithen seither nicht aufmerksatn gemacht worden ist, so glaubten wir diese Thatsache hier anführen zu dürfen, zumal uns dieselbe für die Bildung von Harnsteinen nicht ohne Interesse zu sein scheint, worauf wir uns aber vorbehalten in unserer demnächst bei J. F. Bergmann in

1) O. Lehmann, Molecularphysik. I. Band. Leipzig 1888. S. 350.

2) Derselbe, a. a. O. S. 388 . 
Wiesbaden erscheinenden Monographie „Ueber experimentelle Erzeugung von Harnsteinen durch Füttering" näber einzugehen.

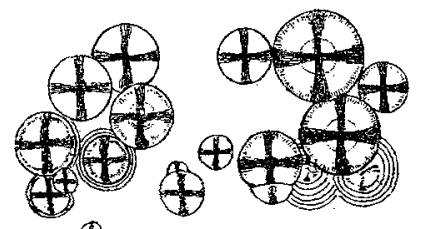

Zeichuung nach einem bei 140 facher LinearVergrösserung aufgenommenen Photogramm von harnsaurew Natron bei gekreuzten $\mathrm{Ni}$ cols.

$\oplus$

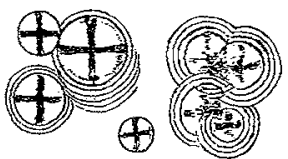

Man siebt auf der Abbildung die im T'ext geschilderten Interferenzerscheinungen.

3.

\section{Vorläufige Mittheilung über eine bakteriolog.-experiment. Untersuchung zur Frage der Puerperaleklampsie.}

Aus dem Pathologischen Institut in Berlin.

Von Dr. Alexandre Favre.

Durch zwei, in füherer Zeit von mir verfasste Arbeiten ${ }^{1}$ ) angeregt, der Eklampsie auf bakteriologischem Gebiet näher zu treten, habe ich Culturen frisch aus den weissen Infarkten der Placenta eines Eklampsiefalles entnomnommen. - Aus diesen Culturen ist es mir möglich gewesen, einen Micrococcus eclampsiae zu isoliren, der einen Durchmesser von $0,7-0,8 \mu$ besass, und, auf Agar oder Gelatine gezüchtet, kleine durchsichtige Punkte bildete. Derselbe war im Stande, häufig leichte Nephritis-Erscheinungen (Harncylinder, leichte parencbymatöse Trübung der Nieren) bei Kaninchen $7 \boldsymbol{n}$ erzeugen. Meine Versuchsanordnung kann in 5 versehiedene Kategorien eingetheilt werden:

1. Injectioneu dieser Culturen in die Blutbaton gesunder Kauinehen bewirkten sebr häufig Temperaturwallungen, meist Senkung derselben.

2. Injectionen von Reinculturen dieser Mikroorganismen in die Blutbahn doppelseitig nephrotomirter Kaninchen verursachten meist ziemlich

1) A. Favre, Uebee d. weissen Infarkt d. menschlichen Placenta. Dieses Arcbiv Bd. 120. Feft 3. 1890 . - Communication provisoire relative à l'étiologie des néphrites gravidiques. Nouv. Areh. d'obst. et de gyn. Paris 1890. 